
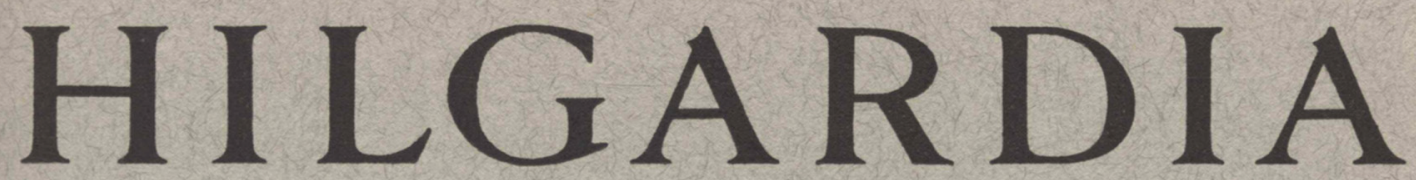

A Journal of Agricultural Science Published by the California Agricultural Experiment Station

\title{
INTERACTION OF ENVIRONMENT AND GENOTYPE IN THE EXPRESSION OF A VIRESCENT GENE, PALE-YELLOW-1, OF MAIZE
}

BERNARD O. PHINNEY and ROBERT E. KAY 
This paper reports the effects of certain environmental factors upon the expression of a virescent mutant, which herein is called paleyellow-1 ( $v-p y-1)$, in maize. The effect of environment has been studied in terms of light duration, temperature, nutrient supply, and the presence and absence of the endosperm. Visual observatians of these factors are interpreted. 


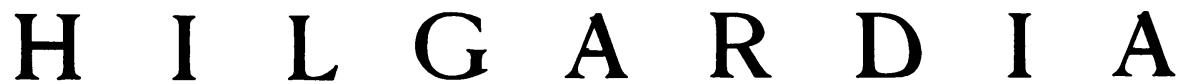

A Journal of Agricultural Science Published by the California Agricultural Experiment Station ERRATUM

VoL. 23

On this publication please change the date of October to December, 1954,

No. 8 wherever it occurs.

\section{INTERACTION OF ENVIRONMENT AND GENOTYPE IN THE EXPRESSION OF A VIRESCENT GENE, PALE-YELLOW-1, OF MAIZE ${ }^{1}$}

\section{BERNARD O. PHINNEY ${ }^{2}$ and ROBERT E. KAY 3}

\section{INTRODUCTION}

Many Gene MUtations are known to affect the plastid pigments of maize seedlings (Emerson, Beadle, and Fraser, 1935 ; et al.). . Some of these result in the development of albino seedlings that are chalk-white in color, without visible evidences of chlorophyll or carotenoid pigments. Other mutants lack chlorophyll only and have varying amounts of carotenoid pigments. The amount of carotenoid pigments is phenotypically expressed as the degree of yellowing evident in the seedlings. This degree of yellowness may range from cream-white seedlings containing almost no carotenoids to bright-yellow seedlings containing an abundance of carotenoid pigments. Some of these mutants are called virescents since, after a lapse of time, they begin to green and often become indistinguishable from normals (Emerson, 1912; Miles, 1915; Lindstrom, 1918; Demerec, 1924). While many of the differences in color between mutant and normal seedlings are associated with morphological changes of the plastids (Miles, 1915; Zirkle, 1929; Schwartz, 1949; et al.), there are examples where the plastids of mutant seedlings are very similar to the plastids of normal seedlings (Schwartz, 1949 ; Koski and Smith, 1951).

The reported variability in the expression of virescence would make it appear difficult to carry out physiological studies with this type of mutant. However, previous studies have invariably been made from seedlings grown in the greenhouse or in the field. While the expression of the virescent character in many mutants is known to be strongly influenced by temperature and possibly by light (Demerec, 1924 ; Emerson, Beadle, and Fraser, 1935), there is no information in the literature on the precise effect of light and temperature when one or the other is varied and the rest of the environment held constant.

In this paper the effects of certain environmental factors upon the expression of a virescent mutation, which herein is called pale-yellow-1 (v-py-1), are reported and the results interpreted in terms of the observed gene differ-

\footnotetext{
${ }^{1}$ Received for publication, March 19, 1954.

${ }^{2}$ Assistant Professor of Botany and Assistant Plant Physiologist in the Experiment Station, University of California, Los Angeles.

${ }^{3}$ Lieutenant, U. S. Naval Radiological Defense Laboratory, San Francisco Naval Shipyard, San Francisco 24, California.

"See "Literature Cited" for citations referred to in the text by author and date.
} 
ence. A later paper will deal with quantitative studies of the pigment content and pigment changes which provide the basis for the visual color differences recorded here between the mutants and their normal sibs.

\section{GENERAL DESCRIPTION OF THE MUTANT}

Appearance. The most obvious effect of the virescent gene pale-yellow-1 is the complete absence of visible chlorophyll in light-grown seedlings during the early stages of seedling growth. As a result, the leaves of mutant seedlings are a uniform pale-yellow when grown in the light (plate 1-A). In addition it was found that the mutants can also be distinguished from normals on the basis of their degree of yellowness. Thus the seedling leaves of dark-grown mutants appear pale-yellow while the leaves of dark-grown normals are

TABLE 1

SIZE AND NUMBER OF PLASTIDS IN MESOPHYLL OF DISTAL 5 CM OF SECOND LEAF OF MUTAN'T AND NORMAL SEEDLINGS*

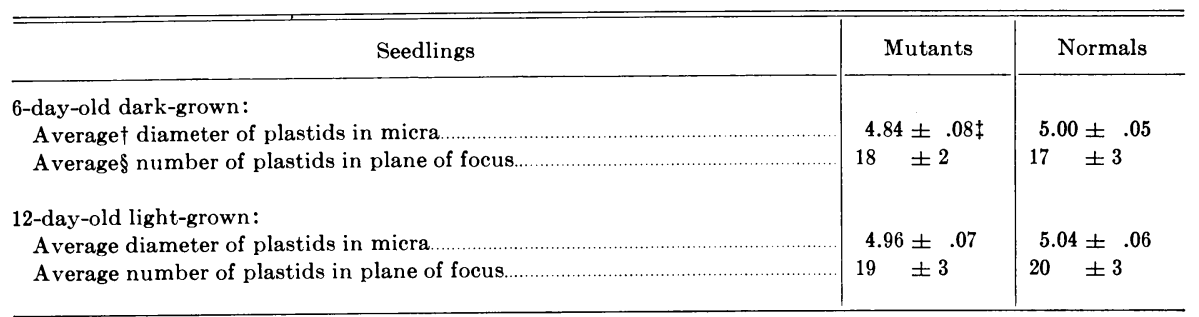

* All material grown at $25^{\circ} \mathrm{C}$. Observations made from microscopic examination of hand sections of living material.

Diameter of 125 plastids taken from 5 different leaves.

$¥$ Standard error of the mean.

$\S$ Number of plastids in plane of focus from 5 different leaves.

bright-yellow (plate 1-B). At constant temperature the seedling mutants are extremely uniform in appearance and clearly distinguishable from normals. At room temperature the pale-yellow character persists for about two weeks. Thereafter these seedlings begin to turn green. Two weeks later they are as green as the normal sibs (plate 2). The size and number of the plastids are very similar in the two kinds of seedlings (table 1 ).

\section{MATERIALS AND METHODS}

The virescent mutant pale-yellow-1 was isolated by Dr. E. G. Anderson of the California Institute of Technology from a "single-cross" (L $289 \times$ L 205) of maize used in the "crossroads" tests of the "able" atomic bomb at Bikini. Pollen from a homozygous mutant plant was crossed to an inbred line and the $F_{1}$ selfed. The $F_{2}$ were found to segregate in a ratio of three normal to one virescent seedling, this indicating that the virescent character is the result of a recessive mutation (Anderson, unpublished data). Subsequent tests to known translocation stocks showed the gene to belong to the fourth linkage group (Anderson, unpublished data). The seed resulting from the selfed $F_{1}$ plants furnished the material used in this study.

Seedlings were grown in sand or nutrient medium. For sand cultures, seed was planted in eight-inch clay pots containing sieved quartz sand which had been previously autoclaved and saturated with water. Detached embryos were cultured in Bonner's (1940) mineral solution to which 0.15 mole of glucose 
and 0.75 per cent agar were added before sterilization (Haagen-Smit, 1945; Tukey, 1934). Before planting, the seed was treated for 20 minutes with 50 per cent Clorox containing 1 gram per liter of the detergent Tide, rinsed in sterile water and soaked for 24 hours. All seedlings were grown in a refrigerator incubator whose dimensions were $5 \times 3 \times 7$ feet. The temperature in this incubator could be controlled to within one-half degree centigrade. A light source was supplied by 13 slim-line fluoreseent lamps, each 72 inches long, spaced 1 inch apart. These lamps were labeled $4500^{\circ}$ white and produced an average light intensity of 700 foot-candles at the surface of the pots, a distance of 55 centimeters from the light source. Two automatic time switches were synchronized so that one turned the lights off and

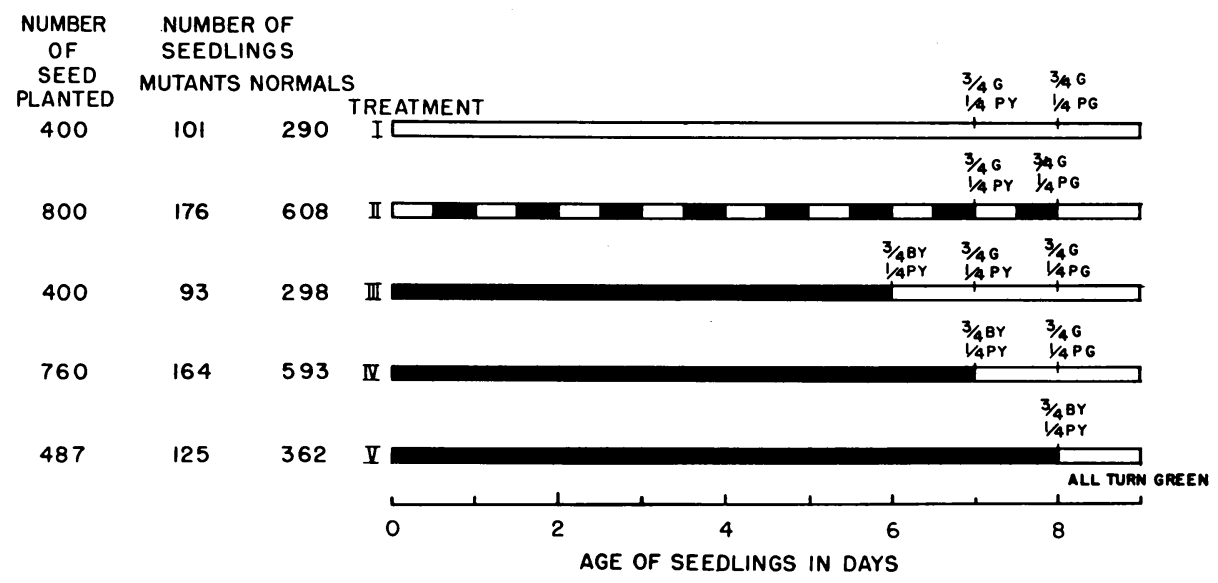

Fig. 1. The effect of darkness and of continuous and intermittant light on the length of time the second leaf of mutant and normal seedlings lacks visible chlorophyll. The solid black indicates periods of darkness; white, periods of light. The horizontal seale is time in days following soaking. Results shown as the visual appearance of the two segregating classes, three normal seedlings to 1 mutant seedling. Normals are classified as either bright-yellow (BY); pale-green ( $\mathrm{PG}$ ), any color ranging from initial greening to $20 \%$ greening; or green $(\mathrm{G})$, any degree of greenness greater than $20 \%$ green. Mutants are either pale-yellow (PY); pale-green (PG); or green ( $\mathrm{G})$.

on and the other reset the refrigeration controls to provide more refrigeration during the light period than during the dark period. Thus a uniform day length of any desired duration could be maintained at a constant temperature.

The data reported in this paper were taken almost exclusively from observations made on the second leaf, counting the first leaf to emerge from the coleoptile as leaf number 1 . Under certain conditions where greening of the seedling leaves occurred before their emergence from the coleoptile, observations had to be made from the seedling leaves enclosed within the coleoptile. Such was the case with light-grown normals and, at the higher temperatures, with light-grown mutants. In all cases the age of the seedlings was considered as time in hours following soaking of the seed.

Specific terms applied to the observed colors of the seedling leaves are listed below. To insure accurate visual description, the leaves were matched with the standard colors found in Dictionary of Color by Maerz and Paul 
(1930). The plate and page number corresponding to each observed color are indicated. When listed, the standard name is also included.

pale-yellow-plate 9, E-1, page 41.

cream-white - plate 9, B-1, page 41.

bright-yellow-plate 9, L-2, page 41.

initial greening in the mutant; chlorophyll is visually present in the mutant. Any part of the leaf is at least as green as chalcedony yellowplate $18, \mathrm{~J}-1$, page 59 .

initial greening in the normal; chlorophyll is visually present in the normal. Any part of the leaf is at least as green as plate 17, L-1, page 57 .

$20 \%$ green in the mutant-plate 18, L-2, citronella, page 59 .

$20 \%$ green in the normal-plate 19, L-5, page 61.

completely green-plate $23, \mathrm{~L}-6$, cypress green or a color having a darker tone, page 69 .

\section{TABLE 2}

RELATION OF TEMPERATURE TO TIME IN HOURS FOLLOWING SOAKING TO REACH INITIAL GREENING IN MUTANT AND NORMAL SEEDLINGS GROWN IN CONTINUOUS LIGHT

\begin{tabular}{l|c|c|c|c}
\hline \hline \multirow{2}{*}{ Temperature in degrees Centigrade } & \multicolumn{2}{|c|}{ Mutant seedlings* $^{*}$} & \multicolumn{2}{c}{ Normal seedlings $\dagger$} \\
\cline { 2 - 6 } & Number & Time in hours & Number & \multicolumn{2}{|c}{ Time in hours } \\
\hline $19 \pm 1$ & 152 & $288 \pm 8(12$ days $)$ & 54 & $32 \pm 3(11 / 3$ days $)$ \\
$25 \pm .5$ & 147 & $184 \pm 6(72 / 3$ days $)$ & 47 & $24 \pm 3(1$ day $)$ \\
$30 \pm .5 \ldots$ & 120 & $96 \pm 4(4$ days $)$ & 58 & $17 \pm 2(2 / 3$ day $)$ \\
$35 \pm . .5$ & 22 & $40 \pm 3(15 / 6$ days $)$ & 69 & $10 \pm 2(1 / 2$ day $)$ \\
\hline
\end{tabular}

* Data from segregating material grown in sand. For all temperatures normal sibs were completely green at the time mutants showed initial greening. At $35^{\circ} \mathrm{C}$ data gathered from material grown in petri dishes.

$\dagger$ Data from segregating material grown on moist filter paper in covered petri dishes. At $35^{\circ} \mathrm{C}$ the time for initial greening of mutants was also recorded. At all temperatures mutants were still pale-yellow at the time normal sibs showed initial greening.

Use of the term $20 \%$ greening requires explanation, since the pattern of greening is not a strictly uniform process. At temperatures of $25^{\circ} \mathrm{C}$ and above, mutants and normals tend to green first at the tip and about the veins of the leaves. At temperatures below $25^{\circ} \mathrm{C}$, mutants and normals green first at the base and about the veins of the leaf. The term $20 \%$ greening is said to occur when the distal $5 \mathrm{~cm}$ of the second leaf blade has a color equivalent to that designated in Dictionary of Color.

To determine the effect of the environment upon greening in the mutants as compared with the normals, the factors of light, temperature, and culture media were varied one at a time and the results recorded. When possible, certain changes in the degree of yellowness of the mutant seedlings were also observed and recorded.

\section{EXPERIMENTAL RESULTS}

Influence of Light Duration. The length of time the mutants remain paleyellow appears to be independent of previous exposure to light. A total of 2,847 seeds that would segregate for normal and virescent seedlings was grown under five different light treatments at $25^{\circ} \mathrm{C}$. Each of these five treatments involved at least 391 seedlings of which 93 or more were mutants. The first treatment was in continuous light, the second in alternating 12 hours of darkness followed by 12 hours of light, the third in 144 hours (six days) 
of darkness followed by continuous light, the fourth in darkness for 166 hours (seven days) followed by continuous light, and the fifth in darkness for 192 hours (eight days) followed by continuous light. Records were taken on the phenotypic appearance of the two classes of seedlings at the time the lights were turned on and over the time period that the mutants changed from pale-yellow to pale-green. In every treatment, mutants were still pale-

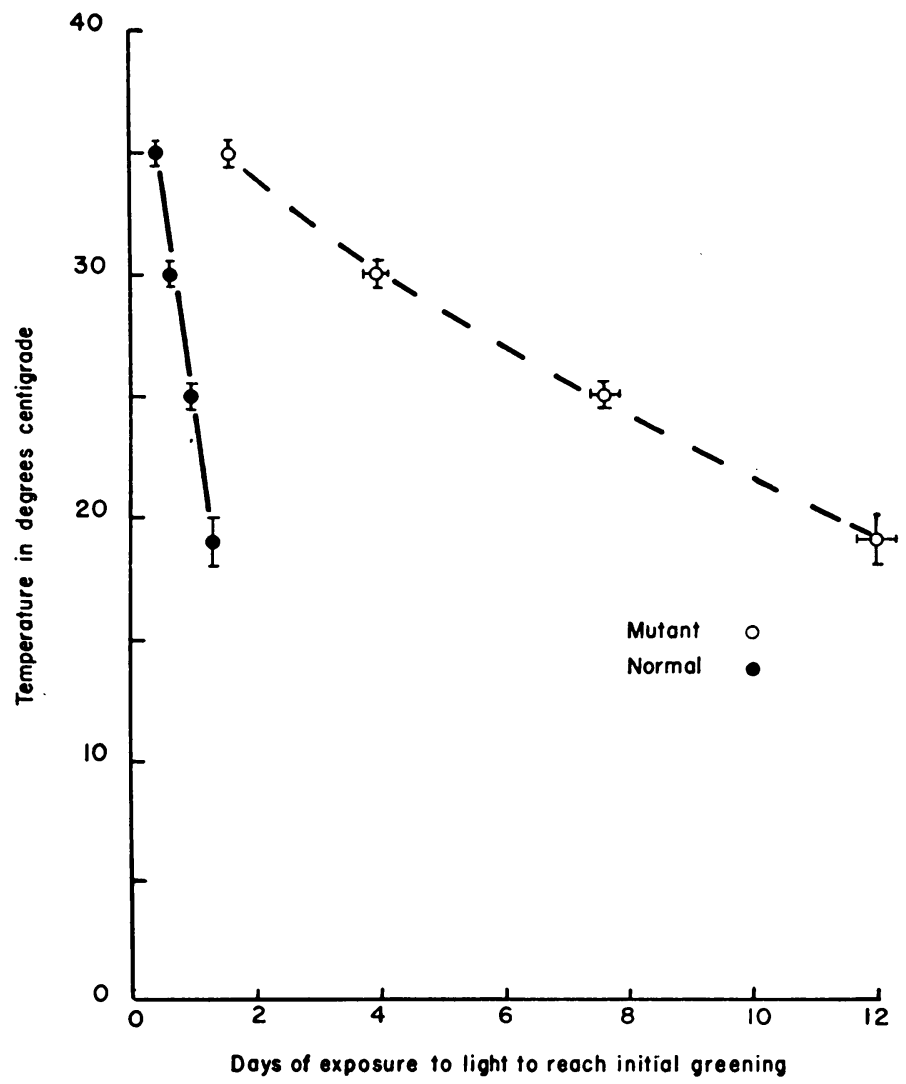

Fig. 2. The length of time mutant and normal seedlings lack visible chlorophyll when grown at different temperatures. Vertical bars represent the range in temperature over which the seedlings were grown, horizontal bars the range in hours over which seedlings were observed to show initial greening. Each point represents the value midway between the two extremes in time over which seedlings were observed to show initial greening.

yellow within the range of $168 \pm 12$ hours (seven days) following soaking, changing from pale-yellow to pale-green within the range of $192 \pm 12$ hours (eight days) following soaking. These relations are diagrammed in figure 1. It is concluded that at a constant temperature of $25^{\circ} \mathrm{C}$, previous exposure to light has little or no influence on the length of time mutants remain paleyellow, and at least $192 \pm 12$ hours (eight days) are required before greening will occur in the mutants when grown at $25^{\circ} \mathrm{C}$.

Influence of Temperature. The length of time before initial greening is evident in mutant seedlings is strongly influenced by temperature. To determine the precise relationship between temperature and the length of time mutant seedlings lack visible chlorophyll, seed segregating for normal and 

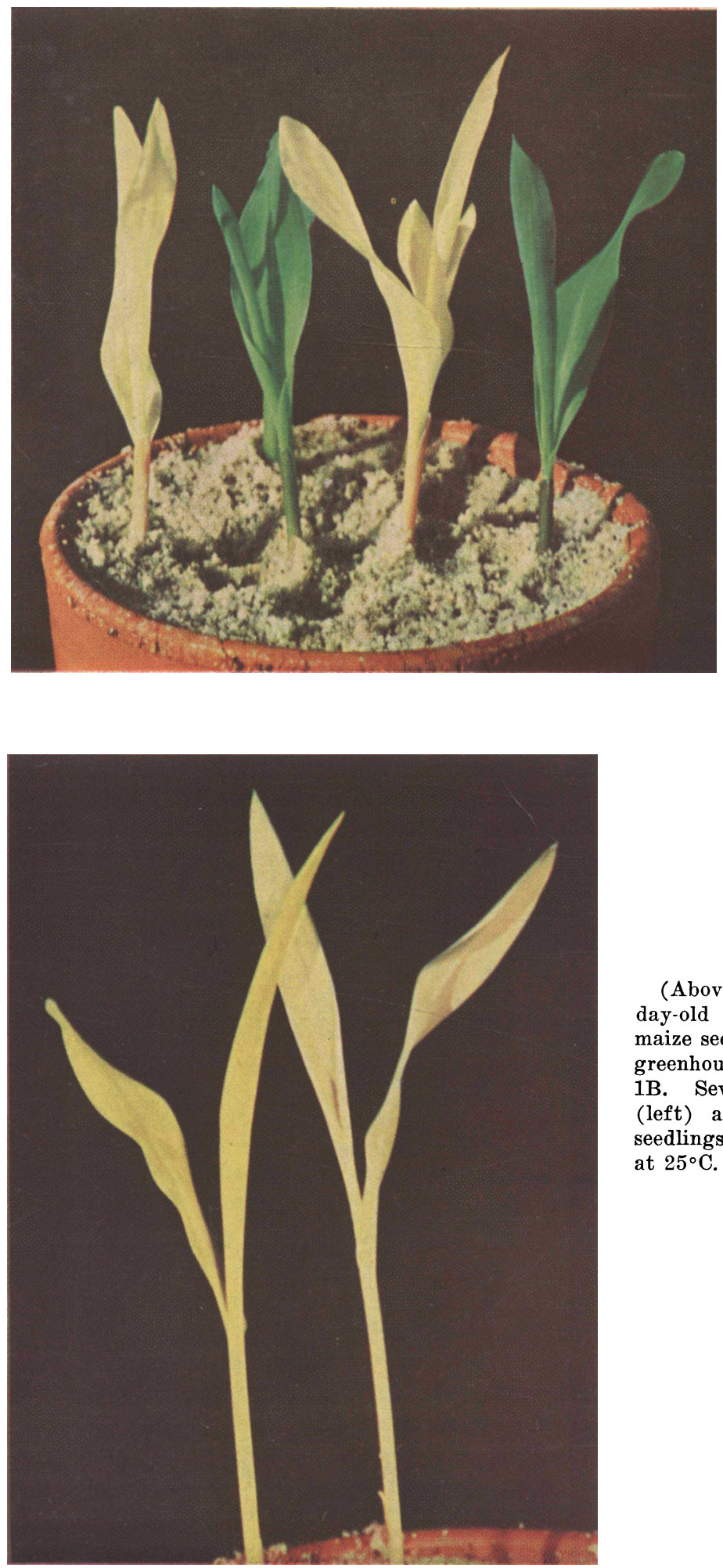

(Above) Plate 1A. Twelveday-old normal and mutant maize seedlings grown in the greenhouse. (Below) Plate 1B. Seven-day-old normal (left) and mutant (right) seedlings grown in the dark at $25^{\circ} \mathrm{C}$. 


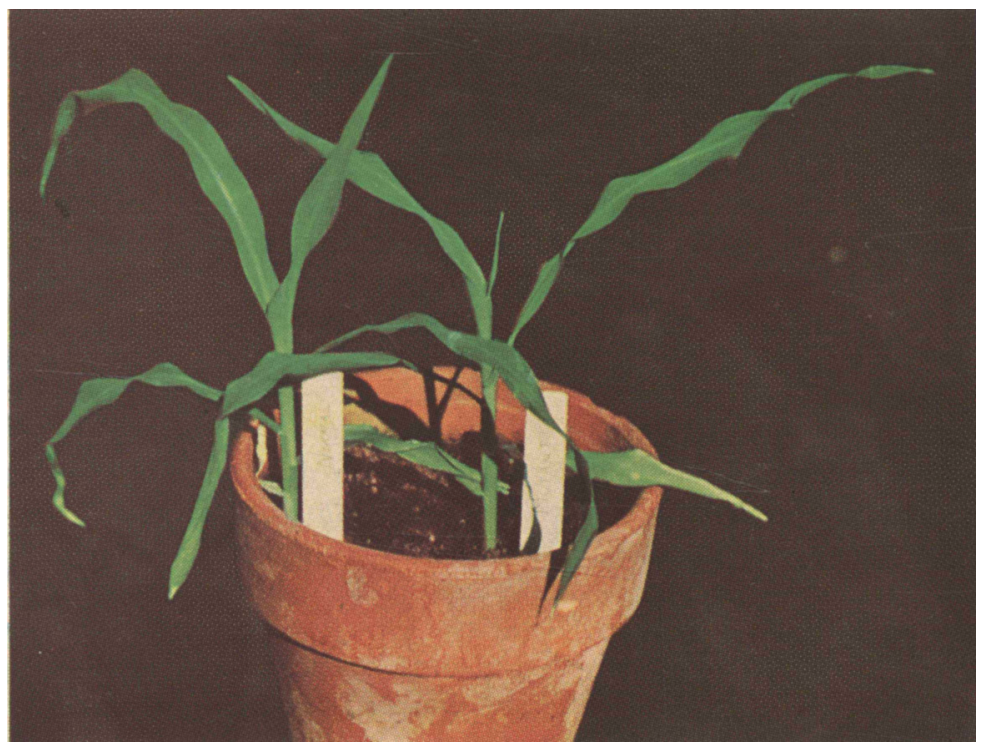

Plate 2. Three-week-old normal (left) and mutant (right) corn seedlings grown in the greenhouse.

virescent plants was grown at $19^{\circ}, 25^{\circ}, 30^{\circ}$, and $35^{\circ} \mathrm{C}$ in continuous light. The length of time for initial greening to occur was recorded from seedlings grown in sand and on moist filter paper in covered petri dishes. The use of petri dishes was necessary since all normal seedlings as well as mutant seedlings grown at $35^{\circ} \mathrm{C}$ showed initial greening in less than 48 hours following soaking. At this age initial greening occurs before the leaves emerge from the coleoptile. For mutants grown at $19^{\circ}, 25^{\circ}$, and $30^{\circ} \mathrm{C}$, observations were made from the second leaf of seedlings grown in sand. Records were taken from a total of 441 mutant and 228 normal seedlings. The data are given in table 2 and graphed in figure 2. It can be seen that the length of time for initial greening to occur in mutant and normal seedlings is inversely related to the temperature; with increasing temperature, this length of time for the mutants approaches that for the normals. It is concluded that the ability of the mutant seedlings to turn green is strongly temperature-dependent.

Influence of Culture Methods. To check the effect of the culture media on the expression of the mutant character, one lot of 70 seeds was grown in soil, a second lot of 100 seeds in vermiculite, a third lot of 580 seeds in sponge rock, and a fourth lot of 541 seeds in quartz sand. Each lot was grown at $25^{\circ} \mathrm{C}$ under a 12-hour day. In all of these media the seedling plants segregated sharply for pale-yellow and green seedlings. The second leaf of pale-yellow mutants did not green until $192 \pm 8$ hours (eight days)following soaking. During this time there was no visible difference in color between mutant plants grown in the various culture media. The expression of the character pale-yellow-1 is considered to be independent of the culture media tested.

Mutant Seedlings Without Endosperm. The influence of the endosperm upon the expression of the mutant character was determined from seedlings 
in which the pericarp and the endosperm had been removed at the time of soaking. One hundred embryos were dissected from sterilized seeds that had been soaked for 24 hours. The pericarp only was removed from a second set of 100 seeds. A third set of 100 intact seeds served as controls. All material was treated for 10 minutes with a 1:1000 mercuric chloride solution containing 1 gram per liter of the detergent Tide, and rinsed three times with sterile water. All material was grown at $25^{\circ} \mathrm{C}$ on the nutrient agar described in materials and methods. Half of each set was grown in the light and half in the dark.

The seedling plants that developed from excised embryos were small with narrow, elongated leaves resembling those of oat seedlings. Embryos without endosperm showed no visible evidences of growth until $72 \pm 12$ hours (three days) after soaking. Intact embryos both with and without the pericarp showed evidences of growth within 12 hours following soaking of the seed. Removal of the pericarp only, had no effect on the growth and appearance of the seedlings. Endospermless plants grown in the dark segregated for creamwhite and pale-yellow seedlings. These two classes corresponded to the paleyellow and bright-yellow segregation of dark-grown plants with endosperm. Prior to the time chlorophyll could be visibly detected, endospermless mutants grown in the light were cream-white. If one subtracts the lag in time before growth is evident, the length of time endospermless mutants lacked visible chlorophyll corresponds closely to the length of time intact mutants lacked chlorophyll.

These data suggest that segregation into mutants and normals is independent of the endosperm and the pericarp ; that the presence of the endosperm contributes to the degree of yellowness in both mutant and normal seedlings; and that the length of time mutant seedlings remain pale-yellow is apparently independent of the presence of the endosperm and the pericarp.

Rate of Greening of Nine-Day-Old Mutant Seedlings. The temperature dependency of chlorophyll accumulation in mutant and normal seedlings was compared by determining the actual time required for the second leaf to reach $20 \%$ greening at each of seven different temperatures. All of these seedlings were grown in the dark at $25^{\circ} \mathrm{C}$ for nine days. This was done to provide mutant material that would be capable of forming chlorophyll upon exposure to light. The rate of greening of the mutants could then be compared with the rate of greening in the normals when exposed to light at the desired temperature. The results from this experiment are shown in table 3 and graphed in figure 3. In the mutants the temperature below which no greening occurred was $16.5 \pm .5^{\circ} \mathrm{C}$. At this temperature mutant seedlings required $109 \pm 18$ hours of exposure to light to reach $20 \%$ greening. This greening resulted in a mottled leaf. At $12 \pm .5^{\circ} \mathrm{C}$ (the lowest temperature used) normal seedlings became $20 \%$ green $96 \pm 18$ hours following exposure to light. Therefore the minimal temperature for greening in the normals is at some temperature below $12^{\circ} \mathrm{C}$. At temperatures of $25^{\circ} \mathrm{C}$ and above, both mutant and normal seedlings reached 20 per cent greening at the same time. From these data it is concluded that: mutant seedlings have a narrower temperature range for greening than do normals; rate of greening in the mutants is less than normal seedling at temperatures between $25^{\circ} \mathrm{C}$ and $16.5^{\circ} \mathrm{C}$; and rates of greening in mutants and normals are indistinguishable from each other at temperatures of $25^{\circ} \mathrm{C}$ and above. 
Development of Yellow Color by Mutant Seedlings. The observation was made that dark-grown seedlings segregate for pale-yellow and bright-yellow plants, corresponding to the pale-yellow and green segregation of light-grown plants. Since pale-yellow mutants grown at $25^{\circ} \mathrm{C}$ in continuous light may be observed to green on the eighth day after soaking, it seemed possible that

TABLE 3

RELATION OF TEMPERATURE TO TIME IN HOURS FOLLOWING EXPOSURE TO LIGHT TO REACH $20 \%$ GREENING*

\begin{tabular}{|c|c|c|c|c|c|}
\hline \multirow{2}{*}{\multicolumn{2}{|c|}{ Temperature in degrees $\mathrm{C}$. }} & \multicolumn{2}{|c|}{ Mutant seedlings } & \multicolumn{2}{|c|}{ Normal seedlings } \\
\hline & & Number $t$ & Time in hours & Number & Time in hours \\
\hline & $\pm .5 \ddagger \ldots$ & 78 & $\begin{array}{l}\text { (no greening in } 3 \\
\text { weeks) }\end{array}$ & 201 & $96 \pm 18 \S$ \\
\hline 15 & $\pm .5 \ldots$ & 94 & $\begin{array}{l}\text { (no greening in } 3 \\
\text { weeks) }\end{array}$ & 297 & $56 \pm 6$ \\
\hline 16.5 & …………......... & 105 & $109 \pm 18$ & 287 & $42 \pm 6$ \\
\hline 19 & $\pm 1 \ldots$ & 89 & $45 \pm 6$ & 305 & $30 \pm 6$ \\
\hline 25 & $\pm .5 \ldots \ldots$ & 85 & $24 \pm 2$ & 302 & $24 \pm 2$ \\
\hline 30 & $\pm .5 \ldots \ldots \ldots$ & 102 & $20 \pm 3$ & 293 & $20 \pm 3$ \\
\hline 35 & $\pm .5 \ldots \ldots \ldots$ & 96 & $15 \pm 3$ & 295 & $15 \pm 3$ \\
\hline
\end{tabular}

* All seedlings grown in the dark for 9 days at $25^{\circ} \mathrm{C}$.

t Number of mutants plus number of normals at any one temperature are the total number of seedlings that germinated from that particular planting.

$\ddagger$ Range in temperature.
Range in hours over which the seedlings were observed to reach $20 \%$ greening.

dark-grown mutants might change in color following the seventh day after soaking. Visible changes in the degree of yellowness are far more difficult to detect than are changes in the degree of greenness. However, under certain conditions it was possible to detect changes in the degree of yellowness as mutants became older.

Eight hundred plants segregating for mutant and normal seedlings were grown in complete darkness for 14 days at $25^{\circ} \mathrm{C}$. At the end of this time an attempt was made to classify the plants into pale-yellow and bright-yellow seedlings. It was found that while there was variation in the degree of yellowness, two distinct color classes no longer existed.

More direct evidence of the changes in yellow color of mutant seedlings was obtained with plants grown at $30^{\circ} \mathrm{C}$. Since changes in color occurred more rapidly at this temperature than at $25^{\circ} \mathrm{C}$, slight changes in the degree of yellowness were more easily detected. Five hundred seeds that would segregate into mutant and normal seedlings were soaked and grown in the dark at $30^{\circ} \mathrm{C}$. On the second day following soaking, the lights were turned on long enough to tag 120 of the seedlings as mutants. Thereafter daily samples of 20 mutants were removed from the dark chamber and compared with the color charts in Dictionary of Color. Even though changes were difficult to observe visibly, a deepening of the pale-yellow color was evident in mutants by the fourth day following soaking. Since mutant seedlings may be observed to green $90 \pm 6$ hours ( $33 / 4$ days) following soaking when grown in the light at $30^{\circ} \mathrm{C}$, it would appear that yellowing begins at the same age as greening. It is concluded that dark-grown mutants turn yellow at a time very close to the time of greening in light-grown mutants. 


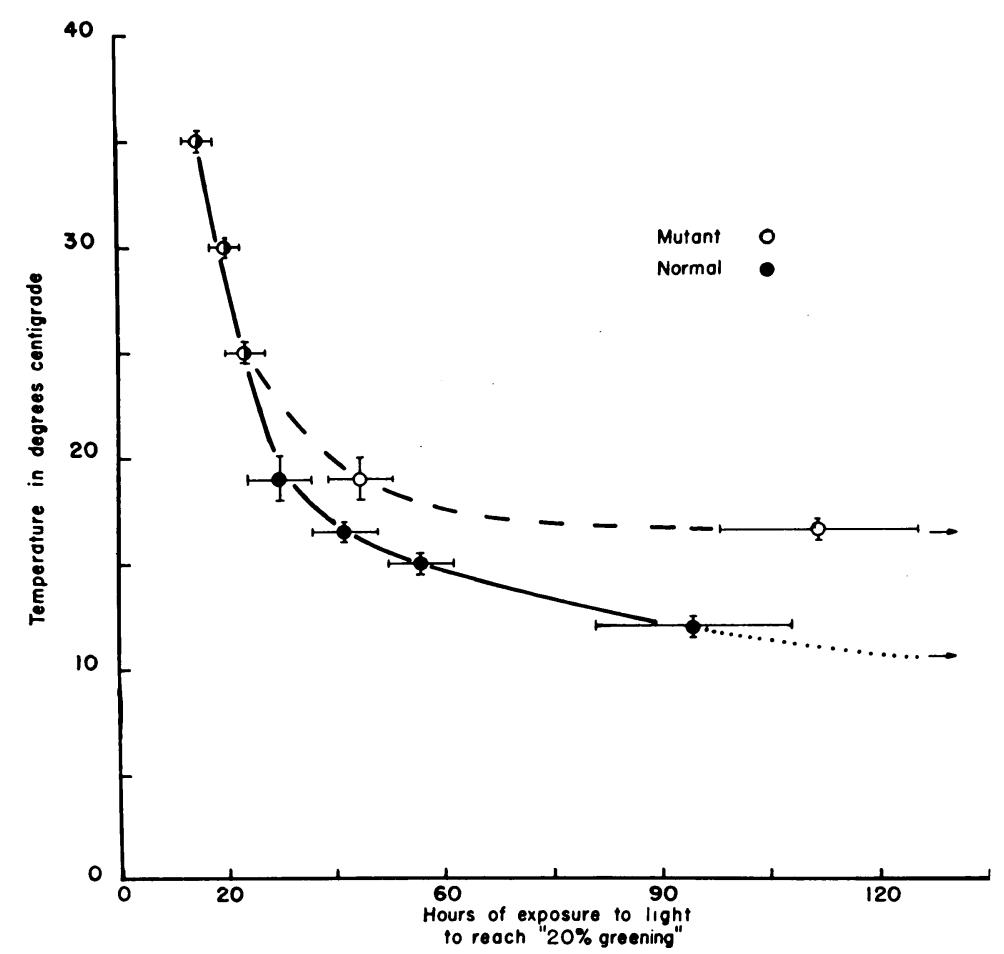

Fig. 3. Length of time for the second leaf to reach $20 \%$ greening following exposure to light at different temperatures. Each point represents the value midway between the two extremes in time over which seedlings were observed to reach $20 \%$ greening. Vertical bars represent the range in temperature in which the seedlings were grown, horizontal bars the range in hours over which the seedlings were observed to show $20 \%$ greening.

\section{DISCUSSION}

The observations show that the mutant seedling pale-yellow-1 is initially uniform pale-yellow when grown in either light or darkness. Exposed to light, these mutants eventually turn green. When kept in darkness they show evidences of turning from pale-yellow to bright-yellow. This time of yellowing corresponds closely to the time of greening. Thus it would seem the mutant gene is controlling the accumulation of both chlorophylls and carotenoids. Plastid size and number are not factors in this delayed appearance of pigments, nor are type of culture media tested and length of exposure to light. On the other hand, the length of time mutants remain pale-yellow is inversely related to the temperature. This inverse relationship between temperature and time suggests that a change in the amount of a limiting factor may control the length of time the mutants remain pale-yellow. Apparently this limiting factor does not involve the endosperm or the pericarp. It is conceivable that this factor involves the ability to produce a compound necessary for both initial greening and yellowing in the mutants.

The presence of the endosperm contributes to the degree of yellowness in both mutant and normal seedlings. It is responsible for almost all of the visible yellow color found in the mutants prior to the time that they would 
green, and for a great deal of the yellow color of dark-grown normals. However, this endosperm effect appears to be independent of the pale-yellow-1 gene since removal of the endosperm results in a decrease in yellowness in both mutant and normal seedlings.

At temperatures above $25^{\circ} \mathrm{C}$, greening in dark-grown, nine-day-old mutants exposed to light proceeds at a rate similar to the rate of greening in comparably grown normals. The relatively abrupt initiation of greening followed by a rapid rate of greening, suggest a trigger mechanism set off by the accumulation of a threshold amount of some substance. Thus the ability to turn green and to turn yellow in the mutants could be limited by the availability of an enzyme, the mutant remaining pale-yellow until this threshold value is reached.

The temperature range over which greening will occur is narrower in the mutants than in the normals. In addition, the rate of greening at temperatures below $25^{\circ} \mathrm{C}$ is slower in the mutants than in the normals. At temperatures above $25^{\circ} \mathrm{C}$, the rates of greening in the mutants and normals are indistinguishable. The higher minimal temperature for greening and the slower rate of greening in the mutants at temperatures between $16.5^{\circ}$ and $25^{\circ} \mathrm{C}$ could conceivably be attributed to a modified enzyme produced under the influence of the mutant gene. Thus when mutants are indistinguishable from normals on the basis of pigmentation, these mutants still show a temperature sensitivity different from normals. In this respect the virescent mutant pale-yellow-1 may be considered to be a temperature-sensitive mutant. Temperature mutants involving the ability to produce specific growth factors at one temperature but not at another temperature are known in Neurospora (Mitchell and Houlahan, 1946; McElroy and Mitchell, 1946). Cases of temperature-sensitive phenotypes associated with the stability of particular enzyme systems have also been reported (Maas and Davis, 1952; Horowitz and Fling, 1953). It is quite conceivable that many of the virescent types of mutations found in higher plants are actually temperature-sensitive mutations.

\section{SUMMARY AND CONCLUSIONS}

The phenotypic appearance of the seedling virescent mutant pale-yellow-1 (v-py-1) in maize has been described. The effect of the environment has been studied in terms of light duration, temperature, nutrient supply, and the presence and absence of the endosperm.

At $25^{\circ} \mathrm{C}$ mutants do not green until $7 \frac{2}{3}$ days after soaking, ultimately becoming as green as normals. The time required for mutants to show initial greening is temperature-dependent, approaching that for normal seedlings at higher temperatures. Evidence suggests that dark-grown mutants become yellower in color at the same time that light-grown mutants green.

The presence of the endosperm contributes to the degree of yellowness in both mutant and normal seedlings, probably operating independently of the mutant gene.

Previous exposure to light, variation in the culture media, and removal of the endosperm are not responsible for the length of time that mutants remain pale-yellow.

For nine-day-old seedlings, the rate of greening is the same for mutants and normals at $25^{\circ} \mathrm{C}$ and above. At temperatures between $25^{\circ} \mathrm{C}$ and $16.5^{\circ} \mathrm{C}$ 
mutants green at a slower rate than normals. The temperature below which greening will not occur is $16.5^{\circ} \mathrm{C}$ for mutants and some temperature below $12^{\circ} \mathrm{C}$ for normals.

An interpretation of these visual observations has been made.

\section{ACKNOWLEDGMENTS}

Thanks are especially due to Dr. E. G. Anderson, Professor of Genetics, California Institute of Technology, Pasadena, California, who provided most of the seed used in these experiments.

BONNER, J.

\section{LITERATURE CITED}

1940. On the growth factor requirements of isolated roots. Amer. Jour. Bot. 27:692-701. DEMEREC, $M$.

1924. Genetic relations of five factor pairs for virescent seedlings in maize. Cornell Univ. Agr. Exp. Sta. Memoir 84:1-38.

EMERSON, R. A.

1912. The inheritance of certain forms of chlorophyll reduction in corn leaves. Nebraska Agr. Exp. Sta. Ann. Rept. 25:89-105.

Emerson, R. A., G. W. Beadle, and A. C. Fraser

1935. A summary of linkage studies in maize. Cornell Univ. Agr. Exp. Sta. Memoir $180: 1-81$.

HAAGEN-SMIT, A. J.

1945. A method for the culturing of excised, immature corn embryos in vitro. Science 101:234.

Horowitz, N. H., and M. Fling

1953. Genetic determination of tyrosinase thermostability in Neurospora. Genetics 38: $360-74$.

Koski, V. M., and J. H. SMITH

1951. Chlorophyll formation in a mutant, white seedling-3. Arch. Bioch. and Bioph. 34: 189-95.

LINDSTROM, E. W.

1918. Chlorophyll inheritance in maize. Cornell Univ. Agr. Exp. Sta. Memoir 13:1-68.

MAAS, W. K., and B. D. Davis

1952. Production of an altered pantothenate-synthesizing enzyme by a temperature sensitive mutant of Escherichia coli. Natl. Acad. Proc. Sci. 38:785-97.

MaErz, A., and M. R. PaUl.

1930. A dictionary of color. 1st ed. McGraw-Hill Book Company, New York.

McElrox, W. D., and H. K. Mitchell

1946. Enzyme studies on a temperature sensitive mutant of Neurospora. Fed. Proc. $5: 376-79$.

Miles, F. C.

1915. A genetic and cytological study of certain types of albinism in maize. Jour. Genet. $4: 193-214$.

Mitchell, H. K., and M. B. HoulahaN

1946. Neurospora IV. A temperature sensitive mutant of Neurospora. Amer. Jour. Bot. $33: 31-35$.

SCHWARTZ, D.

1949. The chlorophyll mutants of maize. Bot. Gaz. 111:123-130.

Tuker, H. B.

1934. Artificial culture methods for isolating embryos of deciduous fruits. Amer. Soc. Hort. Sci. Proc. 32:313-22.

ZIRKLE, C.

1929: Development of normal and divergent plastid types in Zea mays. Bot. Gaz. 88: 186-203. 
The journal Hilgardia is published at irregular intervals, in volumes of about 600 pages. The number of issues per volume varies.

Subscriptions are not sold. The periodical is sent as published only to libraries, or to institutions in foreign countries having publications to offer in exchange.

You may obtain a single copy of any issue free, as long as the supply lasts; please request by volume and issue number from:

\section{Agricultural Publications \\ Room 22, Giannini Hall \\ University of California \\ Berkeley 4, California}

The limit to nonresidents of California is 10 separate issues on a single order. A list of the issues still available will be sent on request.

In order that the information in our publications may be more intelligible, it is sometimes necessary to use trade names of products and equipment rather than complicated descriptive or chemical identifications. In so doing, it is unavoidable in some cases that similar products which are on the market under other trade names may not be cited. No endorsement of named products is intended nor is criticism implied of similar products which are not endorsed. 